\title{
Intrinsic Compression Behavior of Remolded and Reconstituted Clays-Reappraisal
}

\author{
Jie Yin, Yonghong Miao \\ Department of Civil Engineering, Faculty of Civil Engineering and Mechanics, Jiangsu University, Zhenjiang, China \\ Email: yinjie@ujs.edu.cn
}

Received June 2013

\begin{abstract}
Evaluating the impacts of soil structure on mechanical behavior for natural sedimentary clays is an important issue in geotechnical engineering. Burland introduced void index for normalizing the compression curves of various remolded and reconstituted clays to obtain the intrinsic compression line, which provides a reference framework to assess the in-situ compression behavior. However, it does not quantitatively account for the effects of initial water content on compressive behavior of remolded and reconstituted clays and the initial water contents of clays are not always limited to 1.0 - 1.5 times the liquid limits defined by Burland. A modification based on collected tests data was presented on the expressions of $\mathrm{e}_{100}^{*}$ and $C_{c}^{*}$ defined by Burland. Extensive oedometer test data were also collected on various remolded and reconstituted soils with distinct liquid limits and initial water contents to verify the validity of modified expressions. A normalized compression line deduced by intrinsic compression line is proposed in the e-log p plot, which can be used to evaluate the effects of soil structure quantitatively on the intact compressive behavior for natural sedimentary clays.
\end{abstract}

Keywords: Initial Water Content; Compression Behavior; Remolded and Reconstituted Clays; Oedometer Test

\section{Introduction}

When encountered in situ, most natural sedimentary clays show some form of "structure". It has been well accepted that the structure is formed during their depositional and the post depositional processes, where complicated impacts such as mechanical, chemical and biological factors are brought into action [1]. The general term "soil structure" is to mean the arrangement and bonding of the soil constituents, and for simplicity it contains all features of a soil that are different from those of the corresponding reconstituted soil [2-4]. Various experimental data suggests that the mechanical behavior in situ state influenced by the soil structure is totally different from the remolded and reconstituted state [3]. How to quantitatively assess the effects of soil structure on mechanical behavior of natural sedimentary clays is an important issue in geotechnical engineering [3]. For solving this problem, the mechanical behavior of the remolded and reconstituted clays can be used to establish a reference framework [3-5]. The most famous normalized oedometer compression line is the intrinsic compression line (ICL), which provides an available reference frame to assess the in-situ compression behavior proposed. He introduced void index for normalizing the compression curves of various remolded and reconstituted clays hav- ing an initial water content being 1.0 - 1.5 times the liquid limit (preferably 1.25 times). However, it does not quantitatively account for the effects of initial water content although he presented the existing tests data which showed reconstituted clays at higher water contents had higher values of the void ratio at applied stress less than $100 \mathrm{kPa}$. It is well known that natural water contents of natural sedimentary soils vary in a wide spectrum of times liquid limits [5], which are not always limited to 1.0 - 1.5 times the liquid limits.

Based on the existing tests data, the intrinsic compression behavior of remolded and reconstituted clays was briefly investigated and a modification was presented on the expressions of $\mathrm{e}_{100}^{*}$ and $C_{c}^{*}$ defined by Burland for considering both the effects of liquid limit and initial water content. A normalized compressive line is deduced by intrinsic compression line to quantitatively evaluate the effects of soil structure on the intact compressive behavior for natural sedimentary clays.

\section{Compression Curves of Remolded and Reconstituted Soft Clays}

42 different remolded and reconstituted soft clay samples obtained from three different places in China were collected for oedometer tests. Basic physical indices are 
shown in Table 1.

It should be noted that some of the soft clay samples in Label 1 were reconstituted by adjusting its initial water content (reconstituted clays), the others were just only remolded (remolded clays). The initial water contents of the 42 samples range from 0.7 to 2.0 times the liquid limit. The ratio of initial water content $w_{0}$ over liquid limit LL is defined as initial normalized water index $w_{0}^{*}$ [6], which can be expressed as follow

$$
w_{0}^{*}=w_{0} / L L
$$

The typical compressive curves are shown in Figure 1(a), Figure 1(b) and Figure 1(c) for the 42 remolded and reconstituted clays respectively [7]. The legend in each figure represented the initial water contents with the values of $w_{0}^{*}$ being $0.71-1.98,0.68-1.99,0.70-1.99$ of each soil corresponding to Table 1. It can be seen that all the compression curves are similar in shape being slightly concave upwards when the consolidation pressure is larger than some value respectively, as described by Burland [3]. Comparing through the three figures, when the soft clays with about the same initial normalized water index $w_{0}^{*}$, at any given value of the consolidation pressure, the larger the liquid limit, the higher the void ratio is. When concerning any of Figure 1, at any given value of the consolidation pressure, the larger the initial water content, the higher the void ratio and higher compressibility is. However, it is different from that of Burland. It can be concluded that the compressive behavior of remolded or reconstituted clays is influenced by both the liquid limit and initial water content.

\section{Intrinsic Compression Behavior}

Burland stated that the properties of remolded or reconstituted clays are termed 'intrinsic' properties since they are inherent to the soil and independent of the natural state [3]. He presented a useful normalizing index called void index $I_{\mathrm{v}}$ for normalizing the compressive behavior of various remolded and reconstituted clays. The void index is defined as following expression

$$
I_{v}=\frac{e-e_{100}^{*}}{e_{100}^{*}-e_{1000}^{*}}=\frac{e-e_{100}^{*}}{C_{c}^{*}}
$$

The quantities $\mathrm{e}_{100}^{*}$ and $\mathrm{e}_{1000}^{*}$ are the void ratios corresponding to the applied stress $\sigma_{v}^{\prime}=100 \mathrm{kPa}$ and 1000 $\mathrm{kPa}$ of the reconstituted clay at an initial water content $w_{0}$ of $1.0-1.5$ times the liquid limit, respectively. $C_{c}^{*}$ is the intrinsic compression index which equals to $\mathrm{e}_{100}^{*}$ minus $\mathrm{e}_{1000}^{*}$.

Then a reasonably unique compression line termed intrinsic compression line (ICL) is obtained, expressed as follow

$$
I_{v}=2.45-1.285 \mathrm{x}+0.015 x^{3}
$$

where $x=\log \sigma_{v}^{\prime}$ in $\mathrm{kPa}$.

When the oedometer tests are not conducted on the remolded and reconstituted soils, the values of $\mathrm{e}_{100}^{*}$ and $\mathrm{e}_{1000}^{*}$ can be approximately calculated by the following

\begin{tabular}{|c|c|c|c|c|c|c|}
\hline Soil sample number & Sampling site & Gs & $w_{0}(\%)$ & LL (\%) & PL (\%) & $w_{0}^{*}$ \\
\hline $1-14$ & Huaian city & 2.65 & $64.4-179.7$ & 90.6 & 38 & $0.71-1.98$ \\
\hline $15-28$ & Lianyungang city & 2.71 & $50.3-146.3$ & 73.6 & 33 & $0.68-1.99$ \\
\hline $29-42$ & Fuzhou city & 2.67 & $42.6-121.5$ & 61.1 & 30 & $0.70-1.99$ \\
\hline
\end{tabular}
equations (Burland 1990).

Table 1. Basic physical indices of remolded and reconstituted soft clays.

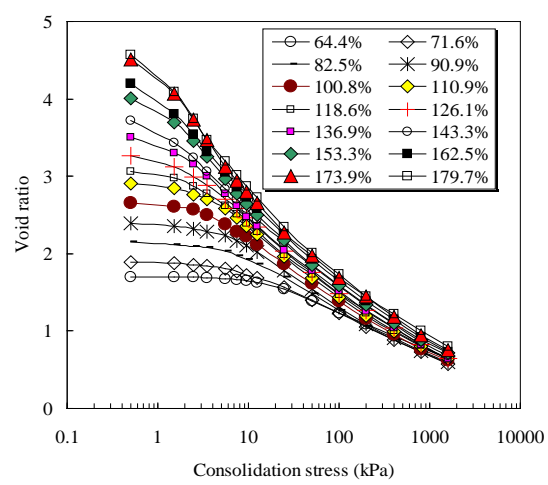

(a)

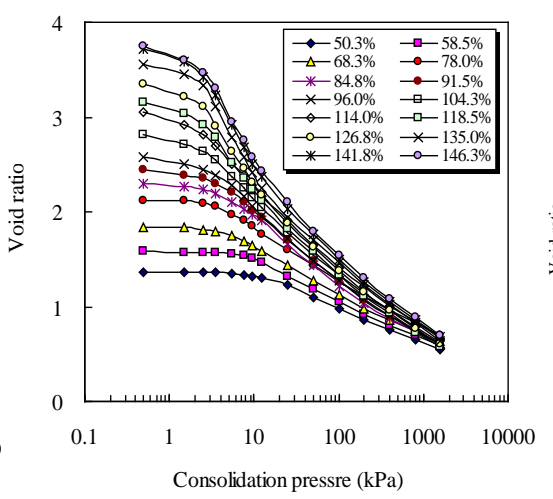

(b)

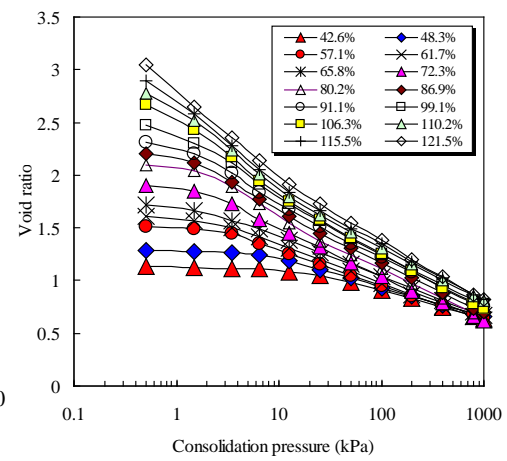

(c)

Figure 1. Typical e-logp compression curves of remolded and reconstituted soft clays (a) Lianyungang city clay, (b) Huaian city clay (c), Fouzhou city clay. 


$$
\begin{aligned}
e_{100}^{*} & =0.109+0.679 e_{L}-0.089 e_{L}^{2}+0.016 e_{L}^{3} \\
C_{c}^{*} & =0.256 e_{L}-0.04
\end{aligned}
$$

where $e_{L}$ represents the void ratio at liquid limit.

Burland has pointed out that the above empirical equations should only be used for values of $e_{L}$ within the range 0.6 to 4.5 (i.e. $w_{L}=25$ to $160 \%$ ).

According to the test data in Figure 1, the compression behavior of remolded and reconstituted clays is obviously influenced by both the liquid limit and initial water content. However, the empirical equation (4) and (5) only consider the effect of liquid limit, for $e_{L}=G_{\mathrm{s}}{ }^{*} L L$ when soil is saturated. That is to say, a modification should be given on Equation (4) and (5) for considering the effect of initial water content.

For simplicity, a liner multiple regression based on tests data in this study is adopted by corresponding computer software. Considering the value of $\mathrm{e}_{100}^{*}$ or

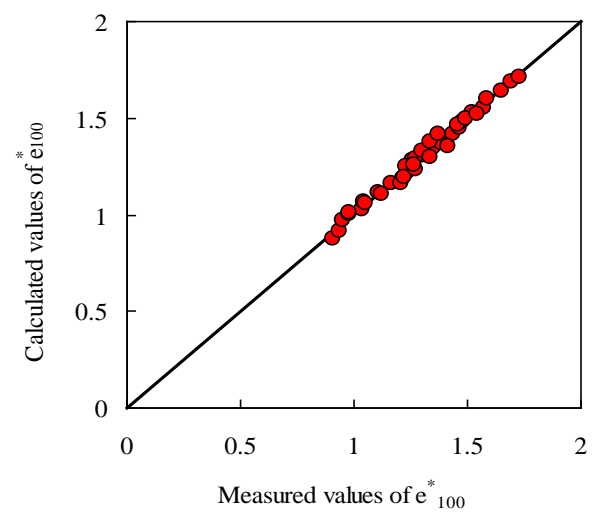

(a)
$C_{c}^{*}$ is increased with the LL from Burland and initial water content or initial normalized water index $w_{0}^{*}$. Based on the 42 tests data, the best fitted quantitative equations are given as follows:

$$
\begin{aligned}
& e_{100}^{*}=1.13 w_{L}+0.39 w_{0} / w_{L}-0.084 \\
& C_{c}^{*}=0.91 w_{L}+0.25 w_{0} / w_{L}-0.461
\end{aligned}
$$

Figure 2 shows the comparison between the measured values of $\mathrm{e}_{100}^{*}$ and $C_{c}^{*}$ from Figure 1 and the calculated values by Equation (6) and (7). It can be seen that they are quite consistent, indicating that Equation (6) and (7) can be used for well predicting the values of $e_{100}^{*}$ and $C_{c}^{*}$.

For further verifying the validity of Equation (6) and (7), several researchers who published oedometer test data of some remolded or reconstituted clays were collected as shown in Table 2.

The comparison results are shown in Figure 3. It is

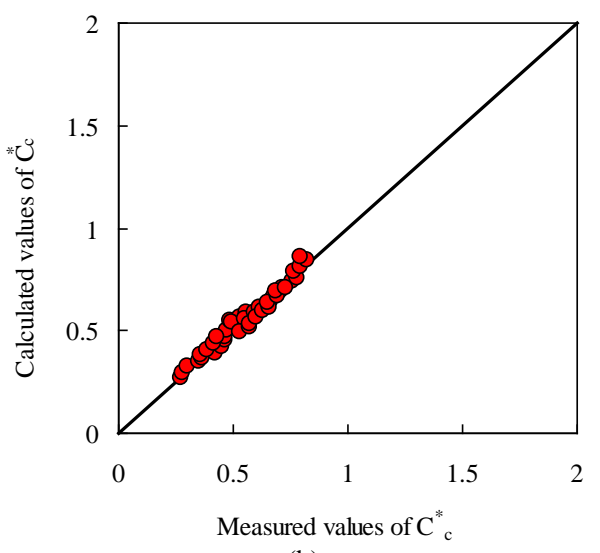

\begin{tabular}{|c|c|c|c|c|c|c|}
\hline Clays & Sample & $G_{\mathrm{S}}$ & $L L(\%)$ & $P L(\%)$ & $w_{0}^{*}$ & Reference \\
\hline Argile Plastique & 1 & 2.58 & 128.0 & 31.0 & 1.00 & [3] \\
\hline London Clay & 1 & 2.71 & 67.5 & 26.5 & 1.00 & [3] \\
\hline Wiener Tegel & 1 & 2.76 & 46.2 & 22.0 & 1.00 & [3] \\
\hline Magnus Clay & 1 & 2.73 & 35.0 & 17.2 & 1.00 & [3] \\
\hline Residual clay & 1 & 2.74 & 58.0 & 27.0 & 1.00 & [3] \\
\hline Red soil & 1 & 2.67 & 45.3 & 22.0 & 1.00 & [6] \\
\hline Black cotton clay & 1 & 2.73 & 97.3 & 32.0 & 1.00 & [6] \\
\hline Red soil & 1 & 2.65 & 50.0 & 27.0 & 1.00 & [8] \\
\hline Brown soil & 1 & 2.65 & 62.0 & 31.0 & 1.00 & [8] \\
\hline Black Cotton Soil & 1 & 2.80 & 84.0 & 47.0 & 1.00 & [8] \\
\hline Ashikari Town clay & 6 & 2.62 & 80.3 & 30.9 & $1.00-1.22$ & [9] \\
\hline Kawasoe Town clay & 2 & 2.65 & 50.9 & 26.6 & $1.00-1.23$ & [9] \\
\hline Ariake Town clay & 14 & 2.60 & 104.8 & 33.9 & $1.01-1.42$ & [9] \\
\hline Kaolinite & 4 & 2.8.0 & 42.0 & 26.0 & $1.00-1.75$ & {$[10]$} \\
\hline Bostion Blue Clay & 4 & 2.68 & 45.0 & 23.0 & $1.00-1.75$ & [10] \\
\hline
\end{tabular}

(b)

Figure 2. Comparison of the $\mathrm{e}_{100}^{*}$ and $C_{c}^{*}$ between calculated and measured values (a) for $\mathrm{e}_{100}^{*}$, (b) for $C_{c}^{*}$

Table 2. Existing data of remolded or reconstituted soils. 


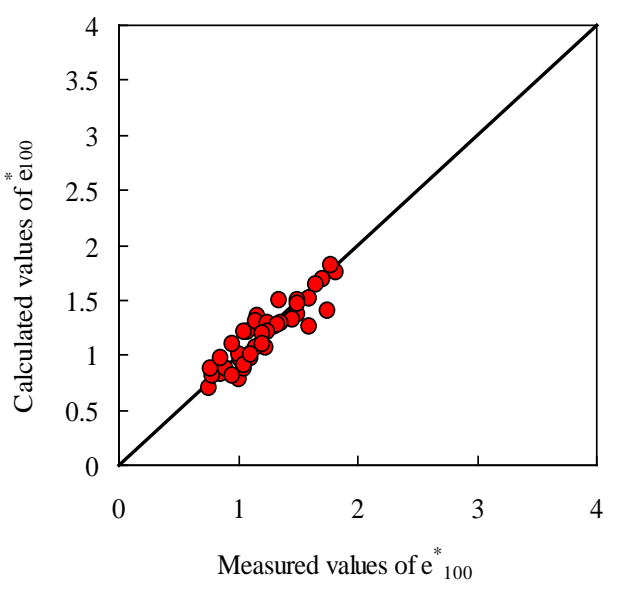

(a)

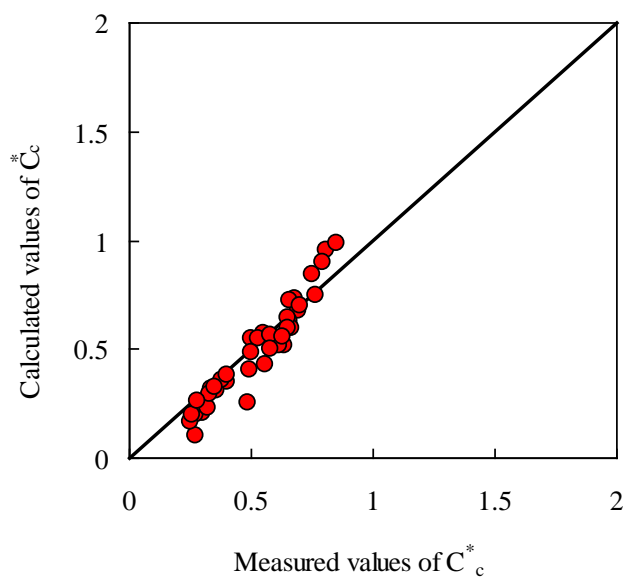

(b)

Figure 3. Comparison of the $\mathrm{e}_{100}^{*}$ and $C_{c}^{*}$ between calculated and measured values in literatures (a) for $\mathrm{e}_{100}^{*}$; (b) for $C_{c}^{*}$.

encouraged that most of the independent data have a close relationship to Equation (6) and (7) although with some data having a little scatter.

Based on the Equation (2), (3), (6) and (7), A normalized compression line considering both the effects of initial water content and liquid limit can be obtained in the e-log p plot written as

$$
e=\left(\left(2.45-1.285 \cdot \log \sigma_{\mathrm{v}}^{\prime}+0.015 \cdot\left(\log \sigma_{\mathrm{v}}^{\prime}\right)^{3}\right) \cdot C_{c}^{*}+e_{100}^{*}\right.
$$

The values of $\mathrm{e}_{100}^{*}$ and $C_{c}^{*}$ can be predicted by Equation (6) and (7) respectively. Equation (8) can be used to evaluate the effects of soil structure quantitatively on the intact compressive behavior for natural sedimentary clays by enabling the initial water content being equal to the natural water content.

\section{Conclusions}

The main conclusions obtained in this study are summarized as follows:

(1) Oedometer tests results for three clays with different initial water contents suggest that the compression behavior of remolded or reconstituted clays is influenced by both the liquid limit and initial water content.

(2) By correlating with the empirical equations proposed by Burland and oedometer test data in this study, a simple form of expressions of $\mathrm{e}_{100}^{*}$ and $C_{c}^{*}$ are obtained by the multiple liner regression, which are

$$
e_{100}^{*}=1.13 w_{L}+0.39 w_{0} / w_{L}-0.084
$$

and $C_{c}^{*}=0.91 w_{L}+0.25 w_{0} / w_{L}-0.461$, respectively.

\section{Acknowledgements}

This research is sponsored by natural science foundation of Jiangsu province in China (Grant No. BK2011476), which is gratefully acknowledged.

\section{REFERENCES}

[1] R. J. Chandler, "Clay Sediments in Depositional Basin: The Geotechnical Cycle,” The Quarterly Journal of Engineering Geology and Hydrology, Vol. 33, No. 1, 2000, pp. 7-39. http://dx.doi.org/10.1144/qjegh.33.1.7

[2] S. Leroueil and P. R. Vaughan, "The General and Congruent Effects of Structure in Natural Soils and Weak Rocks," Géotechnique, Vol. 40, 1990, pp. 467-488. http://dx.doi.org/10.1680/geot.1990.40.3.467

[3] J. B. Burland, "On the Compressibility and Shear Strength of Natural Clays,” Géotechnique, Vol. 40, No. 3, 1990, pp. 329-378. http://dx.doi.org/10.1680/geot.1990.40.3.329

[4] M. D. Liu, J. P. Carter and C. S. Desai, "Modeling ComPression Behavior of Structured Geomaterials," International Journal of Geomechanics, ASCE, Vol. 3, No. 2, 2003, pp. 191-204.

[5] S. Buchan and D. T. Smith, "Deep-Sea Sediment Compression Curves: Some Controlling Factors, Spurious Overconsolidation, Predictions, and Geophysical Reproduction," Marine Georesources and Geotechnology, Vol. 17, No. 1, 1999, pp. 65-81. http://dx.doi.org/10.1080/106411999274016

[6] T. S. Nagaraj and B. R. Srinivasa Murthy, "A Critical Reappraisal of Compression Index Equation,” Géotechnique, Vol. 36, 1986, pp. 27-32.

http://dx.doi.org/10.1680/geot.1986.36.1.27

[7] Z. Hong, J. Yin and Y. Cui. "Compression Behaviour of Reconstituted Soils at High Initial Water Contents,” Géotechnique, Vol. 60, No. 9, 2010, pp. 691-700. http://dx.doi.org/10.1680/geot.09.P.059

[8] T. S. Nagaraj and B. R. Srinivasa Murthy, "Rationalization of Skempton's Compressibility Equation," Géotechnique, Vol. 33, No. 4, 1983, pp. 433-443. http://dx.doi.org/10.1680/geot.1983.33.4.433

[9] Z. Hong, "Void Ratio-Suction Behavior of Remolded Ariake Clays," Geotechnical Testing Journal, Vol. 30, No. 3, 2007, pp. 234-239. 
[10] A. B. Cerato and A. J. Lutenegger, "Determining Intrinsic Compressibility of Fine-Grained Soils,” ASCE Journal of
Geotechnical and Geoenvironmental Engineering, Vol. 130, No. 8, 2004, pp. 872-877. 